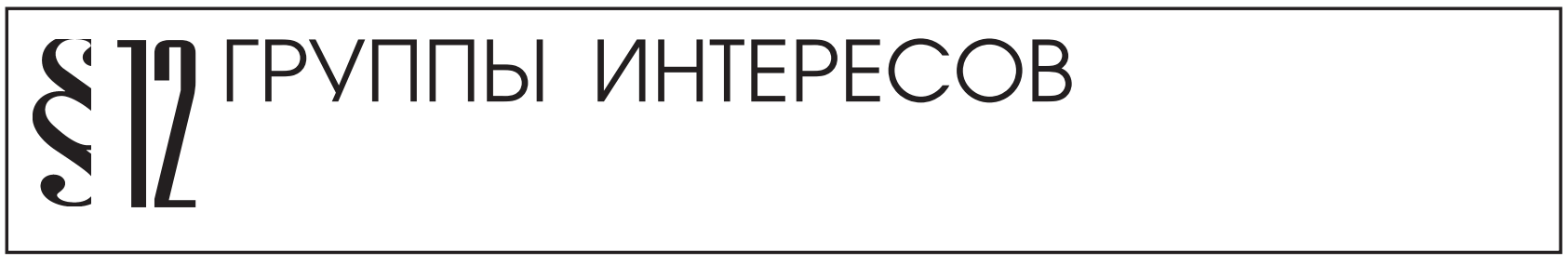

Максимов А.A.

\title{
ПОДРАЖАНИЕ КАК СПОСОБ ПОВЫШЕНИЯ КОНКУРЕНТОСПОСОБНОСТИ ОРГАНИЗАЦИИ
}

\begin{abstract}
Аннотация: B статье рассматривается организаџионная стратегия подражания как альтернатива инновационному развитию организации. Выявлены особенности и методология стратегии подражания. Стремление кгомогенизации организаций, входящих в одно поле обоснованное в рамках теории институционального изоморфизма, объясняет почему со временем можно наблюдать все больше схожих черт у организачий, действующих на рынке. Проиесс гомогенизаиии, однако, не является стихийным, а представляет собой вполне осознанный стратегический шаг в сторону повышения организационной эффективности. Так, посредством копирования моделей более успешных организаций, а также отдельных элементов организационных структур, процессов и продуктов, многие ныне всемирно известные организации достигли лидирующих позищий на рынке. Мировой опьыт свидетельствует о том, что стратегия подражания и имитации не уступает, а часто и превосходит по эффективности стратегию инновационного развития организаций. Подражание и имитация как предмет научных исследований набирает все большую популярность в последние годы.

Review: The article is devoted to a company's imitation strategy as an alternative to innovative development. The author of the article defines peculiarities and methods forming the basis of imitation strategy. Companies functioning in one field tend to become homogenous which is explained by the author from the point of view of institutional isomorphism. According to the author, this is why we can see similar features in different companies acting on the same market. Homogenization however is not a spontaneous process but a rather deliberate strategic step towards improving company's performance. For example, through imitating more successful companies and particular elements of their organizational structures, processes and products many companies that are world-famous now have achieved their leading positions on the market. Global experience shows proves the imitation strategy to be no less or sometimes even more effective than the strategy of innovation-based development. As the topic of research imitation and mimesis have been growing more important lately.
\end{abstract}

Ключевые слова: подражание, имитация, изоморфизм, подражательный изоморфизм, инновационная стратегия, гомогенизация, организационное поле, подражатели, инноваторы, организационное развитие

Keywords: imitation, mimesis, isomorphism, mimetic isomorphism, innovation strategy, homogenization, company's field, imitators, innovators, company's development.

$\mathrm{O}$ рганизация как система существует во имя достижения цели (или целей). Еще А.А.Богданов в своей организационной теории ${ }^{1}$ указывал, что любую форму организации можно описать с точки зрения объективной целесообразности составляющих ее элементов и их взаимосвязей. Целесообразное устройство можно наблюдать в биологических, механических, политических, социальных, культурных,

\footnotetext{
${ }^{1}$ Богданов А.А. Тектология. Всеобщая организационная наука. М.: Финансы, 2003 - §4. Прообразы тектологии.
}

экономических и других видах систем. Целесообразность в первую очередь связана с рациональностью устройства, то есть со стремлением системы максимально эффективно достигать поставленных целей и решать текущие задачи, минимизируя при этом затрачиваемые усилия.

Социально-экономические организации основаны на идее целесообразности, цель формирует их рациональную структуру. Например, если целью такой социально-экономической как коммерческая является повышение ее эффективности, выражающееся в стремлении к получению максимально возможной прибыли, 
то деятельность всех составляющих ее подразделений будет направлена на достижение этой цели.

Конкурентоспособность организации напрямую зависит от правильно выбранной цели развития. Одно из главных различий между этими целями заключается в том, что одни из них являются новыми, теми, которые еще никто и никогда не ставил, а другие только корректируют цели уже существующих компаний. Принципиальным становится вопрос о том, пытаться ли достичь успеха посредством внедрения новшества или же следовать примеру более успешных организаций?

Стратегия инновационного развития организации зачастую сопряжена с высокими рисками и расходами. Нововведения требуют повышенного напряжения организации, затрат сил, времени и средств на его освоение за счет внутриорганизационных ресурсов. Главным образом это касается радикальных нововведений: реорганизации, замены производственных мощностей, смены целей и стратегии, реформ. Традиционно в инновационном процессе выделяют четыре стадии ${ }^{2}: 1$. Фундаментальные исследования (финансирование из бюджета на безвозвратной основе) 2. Исследования прикладного характера (как правило, совмещение государственного финансирования и заказчика) 3. Экспериментальные разработки в лабораториях и экспериментальных производствах (к источникам финансирования прибавляются собственные средства организации) 4. Процесс коммерциализации (требуются большие инвестиции в производство). Инновация - мощная сила, важный фактор жизнеспособности, роста и процветания компаний, а также источник монопольных прибылей. Однако ввиду того, что инновационный период влечет с собой дополнительные затраты, восполнимость которых не гарантирована, большинство организаций следуют стратегии подражания лидерам в своей отрасли.

Инновации, бесспорно, являются двигателем прогресса и экономического роста отдельных организаций, государств и всего человечества. Поэтому мировая общественность в целом проявляет заинтересованность в их появлении, тогда как копирование инноваций не вызывает такого поощрения, что, разумеется, справедливо.

Стратегия подражания также в последнее время вызывает немалый научный интерес. Наоборот, вопросам стратегии подражания и ее результатам посвящаются статьи и монографии, в которых авторы зача-

${ }^{2}$ Слабов С.С. Основы менеджмента: Курс лекций. М.: Изд-во МГУ, 2004. - с.73 стую приходят к выводам о том, что эффективность копирования отдельных элементов или даже моделирование своей организации по образу более успешной - эффективный путь к ее процветанию. Весомым аргументом в поддержку этого тезиса являются статистические данные, согласно которым в течение последних 50 лет 97,8\% доходов от использования инноваций шло в карман организаций, следовавших стратегии подражания ${ }^{3}$.

Наличие экстра-ресурсов у инноватора делает его неповоротливым в условиях, когда нужно повторять одинаковые бизнес-процессы и оттачивать их эффективность. Инноватору часто проще придумать что-то новое, чем заниматься рутинной работой. В любом случае его рутинная работа будет менее рентабельной, чем у последователя, не тратящего ресурсы на поиск нового.

Согласно тории П. Димаджио и У.В. Пауэла ${ }^{4}$ организации функционируют в определенной среде, которая, делает их изоморфными по отношению друг к другу. Исследователи вводят понятие организационного поля, составляющего идентифицируемую сферу институциональной жизни. На ранних стадиях жизненного цикла поля, наблюдается существенное разнообразие форм входящих в него организационных структур. Однако когда поле сформировано, в нём обнаруживается непреодолимая тяга к гомогенизации. Высоко структурированные организационные поля создают контекст, в котором индивидуальные попытки рационально справиться с неопределённостью и ограничениями часто приводят на агрегированном уровне к единообразию структуры, культуры и результатов деятельности организаций.

Это единообразие входящих в одно поле организаций, исследователи называют изоморфизмом. А. Хоули ${ }^{5}$ описывает изоморфизм как ограничивающий про-

3 Dr.YKK (Kam Keong Yew) Copycat Innovation: The Unbeatable Fast-track Route to Profitable Innovation, $2011 / /$ www.mindbloom.net

${ }^{4}$ П. Дж. Димаджио, У. В. Пауэлл Новый взгляд на «железную клетку»: институциональный изоморфизм и коллективная рациональность в организационных поля// Экономическая социология. Т. 11. № 1. Январь 2010

${ }^{5}$ Hawley E. W. 1966. The New Deal and the Problem of Monopoly: A Study in Economic Ambivalence. Princeton: Princeton University Press. // Цит. по: П. Дж. Димаджио, У. B. Пауэлл Новый взгляд на «железную клетку»: институциональный изоморфизм и коллективная рациональность в организационных поля// Экономическая социология. Т. 11. № 1. Январь 2010 


\section{Политика и общество $10(106) \cdot 2013$}

цесс, который вынуждает единицу популяции быть похожей на другие единицы, существующие в условиях той же среды. П. Димаджио и У.Пауэлл выделили 3 механизма институционального изоморфизма: принудительный, подражательный и нормативный. Каждый из перечисленных механизмов призван объяснить причину сходства организационных структур одного поля. Принудительный изоморфизм опирается на утверждение о том, что одна организация (например, государство) определяет структуру и образ действий организаций, входящих в соответствующее поле. Нормативный изоморфизм выражается в том, что представители различных профессий в рамках организации демонстрируют значительное сходство с представителями аналогичных профессий в других организациях.

В контексте данной темы интерес для нас представляет подражательный изоморфизм. Подражательный изоморфизм определяется тем, что в условиях неопределенности одни организации начинают моделировать себя по образу и подобию других. В основном организации склонны моделировать себя по образцу сходных организаций в том же поле, воспринимаемых ими как более легитимные или успешные. ${ }^{6}$ При этом копироваться могут не только структура, но и процедуры, продукты, процессы, бизнес-модели и способы взаимодействия элементов внутри организации.

Разделяя организации одного поля на центр и периферию, П. Димаджио и У.В. Пауэл подчеркивают их изначально неравный статус. Модель подражания организаций входящих в одно поле можно описать следующим образом. Компании-инноваторы (центр) первыми внедряют новшества, благодаря чему обретают преимущество перед конкурентами. Одновременно, однако, они служат для заимствующих организаций (составляющих периферию) удобным источником практик, которые та может использовать. Со временем инновация получает широкое распространение, что

\footnotetext{
${ }^{6}$ Однако, как отмечает Дж. Мейер, повсеместное проникновение некоторых структурных элементов можно связать скорее с универсальными подражательными процессами, чем с какими-либо конкретными доказательствами того, что освоенные модели повышают эффективность. В [7] Дж. Мейер, например, утверждает, что легко предсказать, как будет организована администрация недавно возникшего государства, даже не зная ничего о самой стране, поскольку периферийные страны гораздо более изоморфны в отношении административной формы и экономических образцов, чем можно предположить, руководствуясь любой теорией мировой системы экономического разделения труда.
}

приводит к гомогенизации организационных структур одного поля. Таким образом, изоморфный цикл завершается до появления очередной инновации.

Подражание также как инновационная стратегия развития является результатом рационального поведения организации в условиях конкуренции. В своей книге О.Шенкар 7 утверждает, что подражание не только необходимо для выживания и процветания бизнеса как и инновация, но и жизненно необходимо для реализации инновации как таковой. Подражание, с его точки зрения, представляет собой редкую и сложную стратегическую способность. В то время как инноваторы прокладывают новые пути и вкладывают в это немалые средства, компании-подражатели следуют за ними по бесплатному билету, экономя не только на НИОКР, но и на рекламе, поскольку покупатели уже готовы использовать новый продукт или услугу. Это имеет особое значение в тех отраслям предпринимательства, где требуются крупные инвестиции в исследования и разработку инновации. Примером может служить такая отрасль как фармацевтика, где миллиарды долларов тратятся компаниями на разработку новых препаратов, большая часть из которых не проходят этап клинических исследований. Таким образом, общие затраты компаний-подражателей значительно ниже и обычно равны $60-75 \%$ от затрат инноваторов ${ }^{8}$. Эта экономия, а также более поздний выход на рынок позволяет им сосредоточить усилия на исправлении недостатков первых предложений и усовершенствовать их, с учетом потребностей потребителей.

Компании подражатели, в отличие от первопроходцев рынка не проигрывают в конкуренции за доминирующий стандарт. Более того, стратегия подражания часто позволяет им обойти самих инноваторов и стать лидерами отвоеванного рынка. Так, например, первые кредитные карты были выпущены сетью Diners Club, но сегодня ей принадлежит микроскопическая доля рынка, тогда как лидерами являются Visa, MasterCard и American Express, которых и в помине не было, когда Diners Club вела неравную борьбу за продвижение новой идеи среди банков, торговых фирм и клиентов. Другим аналогичным примером такой ситуации является White Castle. Ее основатель -

\footnotetext{
7 О. Шенкар Имитаторы. Как компании заимствуют и перерабатывают чужие идеи, М.: Альпина Паблишерз, 2011 , с. 16

${ }^{8}$ Там же, с. 20
} 
Уолтер Андерсен - первым придумавший в 1921 г. концепцию и систему сети точек быстрого питания, обнаружил, что толпы конкурентов перенимают у него все, от дизайна до операционных процедур. В скором времени самые ловкие и эффективные из этих имитаторов (к числу которых относится всемирно известный McDonald's) превзошли оригинал, который сегодня является незначительным игроком созданного им огромного рынках 9 . Еще одним примером является компания Samsung, основатель которой - Ли Кун-И - следовал стратегии «быть первым после инноватора». В результате, Samsung является всемирно известным брендом, а ее рыночная стоимость сегодня превышает \$140 млрд. В Таблице 1 представлены дополнительные примеры успешных подражателей. анализа и обобщения результатов были выявлены характерные черты подражания ${ }^{11}$ :

1. Измеримость результатов

2. Соблюдение прав интеллектуальной собственности

3. Низкие риски, ввиду применения уже опробованных решений

4. Низкая стоимость, ввиду отсутствия необходимости проводить исследования и разработку

5. Кратчайший путь к коммерциализации

Была также разработана модель, получившая название «7 шагов к копированию инновации». Ее автор Ю Кам Кьонг, занимаясь исследованием причин эффективности стратегии подражания пришел к выводу о том, что успех организации на рынке во многом

Таблийа 1. Подражатели и инноваторьы ${ }^{10}$ [8]

\begin{tabular}{|c|c|c|c|}
\hline № & Инноватор & $\begin{array}{c}\text { Отрасль } \\
\text { предпринимательства }\end{array}$ & Подражатель \\
\hline 1 & Nutrilite & Маркетинг & Amway \\
\hline 2 & White Castle & Быстрое питание & McDonald's \\
\hline 3 & Netscape & Интернет браузеры & Internet Explorer \\
\hline 4 & Royal Crown Cola & Диетические напитки & Coca-Cola \\
\hline 5 & deHavilland & Коммерческие авиалайнеры & Boeing \\
\hline 6 & Raytheon & Микроволновые печи & Samsung \\
\hline 7 & Apple & Операционные системы & Microsoft \\
\hline 8 & Diners Club & Кредитные карты & Visa \\
\hline 9 & The Point & Социальные проекты & Groupon \\
\hline
\end{tabular}

Высокоэффективные результаты применения стратегии подражания не могли не вызвать научного интереса к ее более глубокому изучению. Так, в результате

\footnotetext{
${ }^{9}$ Hogan, D. G. 2007. Selling'em by the sack: White Castle and the creation of American food. New York: NYU Press; Rivkin, J. W. 2001. Reproducing knowledge: Replication without imitation at moderate complexity. Organization Science 12, 3, 274-293, Big bite. 2008. Economist, April 26, p. 107.// Цит. по: О. Шенкар. Имитаторы. Как компании заимствуют и перерабатывают чужие идеи, М.: Альпина Паблишерз, 2011, с. 14

10 Dr.YKK (Kam Keong Yew) Copycat Innovation: The Unbeatable Fast-track Route to Profitable Innovation, $2011 / /$ www.mindbloom.net
}

зависит от логики рассуждения и последовательности совершаемых ею шагов ${ }^{12}$.

Шаг 1: Определение ключевой проблемы. Под этим автор подразумевает определение глубинных причин того или иного явления, а не устранение симптомов.

Шаг 2: Использование «подхода Микеланджело». Вместо того, чтобы следовать обычному подходу к решению проблемы, двигаясь из пункта А к поставлен-

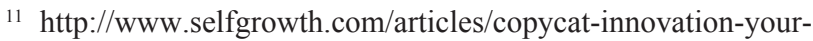
secret-weapon-to-trounce-your-competition

12 Dr.YKK (Kam Keong Yew) Copycat Innovation: The Unbeatable Fast-track Route to Profitable Innovation, $2011 / /$ www.mindbloom.net
} 


\section{Политика и общество 10 (106) • 2013}

ной цели, автор предлагает вначале визуализировать конечный результат, и затем двигаться к его достижению, постепенно отсекая ненужные части от целого.

Шаг 3: Глобальный поиск решений. Прежде чем опробовать новые идеи лучше изучить опыт решения аналогичной проблемы другими организациями, в том числе представляющими другие отрасли предпринимательский деятельности.

Шаг 4: «Придумывание колеса». Суть данного этапа заключается в отсутствии необходимости придумывать новые решения проблемы, когда найдено уже готовое и положительно зарекомендовавшее себя решение. Все, что нужно - это адаптировать его к данной конкретной ситуации.

Шаг 5: Обеспечение условий реализации решения. Включает выделение бюджета, логистику, маркетинг, обеспечение человеческими ресурсами.

Шаг 6: Реализация решения

Шаг 7: Осознание и празднование победы. Необходимый этап, который позволит всем участникам проекта почувствовать себя частью целого.

Говоря о стратегии подражания, следует отметить, что помимо достижения чисто прагматических целей организаций этот процесс несет в себе ряд латентных социально-экономических функций. Во-первых, благодаря ему происходит повсеместное распространение инновационных продуктов и решений, что само по себе имеет колоссальное значение для социально-экономического развития. Во-вторых, в экономическом плане появление конкуренции на рынке инноваций является ключевым фактором в процессе ценообразования и лишает организацию инноватора статуса монополиста. В-третьих, благодаря непрекращающемуся процессу подражания происходит эволюция инновации. Поэтому участников этого процесса О. Шенкар предлагает называть имоваторами (инноватор + имитатор), что в целом справедливо, поскольку адаптируя инновацию под конкретные условия организации совершенствуют ее качественные характеристики, удешевляют и т.д.

Таким образом, перед организацией всегда стоит выбор, каким из двух путей ей двигаться к достижению целей развития и процветания: путем внедрения инноваций или посредством подражания инноваторам. В данной статье были рассмотрены преимущества стратегии подражания как наиболее эффективного метода достижения организационных результатов. При этом нисколько не умаляется значение инновационного развития.
Следует обратить внимание на то, что государственные и корпоративные организационные системы различным образом воспринимают стратегию подражания. Традиционный менеджмент, «ведущий свою родословную» от предпринимательства, всегда боготворил инновации. Следование за конкурентами, несмотря на то, что этой стратегией пользуются более 90\% фирм, всегда воспринимается как слабая и не достойная подробному исследованию и популяризации. Государства же, особенно в конце XX, начале XXI столетий, постоянно копируют друг друга. Появилась даже некоторая идеальная модель демократического государства, которой должны следовать все буквально по всему миру. Понятно, что в основе этой модели лежит американский или, при более широком взгляде, западный опыт с его устройством государственной машины и соответствующей идеологией. Любые новации в государственном устройстве подвергают страну риску попасть в ряд «странизгоев». Опыт М. Каддафи очень показателен в этом плане. Процесс глобализации на сегодня однозначно связывается в сфере организационно-государственном устройстве с приоритетом унификации и подражания. Ограничения такого сценария развития человечества становятся в настоящее время все более и более очевидными. Подражание и здесь должно стать основой продуманных инноваций, способных создать подлинное разнообразие социальных процессов и сценариев жизни людей. Как и в частно-корпоративном секторе, в государственном устройстве должен был найден разумный баланс между подражанием и инновациями.

Опираясь на вышесказанное нужно признать правильность двух утверждений. Во-первых, необходимо, избавившись от клише о том, что подражание - это неверный путь организационного поведения, согласиться с тем, что это наиболее эффективный и мало затратный путь развития организации. Во-вторых, подражание стоит рассматривать в качестве отправной точки к совершенствованию и разработке инноваций. Думается, что эти выводы позволят переоценить роль стратегии подражание, а научные исследования в этой сфере помогут выработать подходящую модель эффективной стратегии подражания и адаптации продуктов инновационной деятельности с последующей перспективой их совершенствования в отечественных условиях. 


\section{Библиография:}

1. Богданов А.А. Тектология. Всеобщая организационная наука. М.: Финансы, 2003

2. Мишин С.А. Проектный бизнес. Адаптированная модель для России . -М.:АСТ, 2006

3. П. Дж. Димаджио, У. В. Пауэлл Новый взгляд на «железную клетку»: институциональный изоморфизм и коллективная рациональность в организационных поля// Экономическая социология. T. 11. № 1. Январь 2010

4. О. Шенкар Имитаторы. Как компании заимствуют и перерабатывают чужие идеи, М.: Альпина Паблишерз, 2011

5. Bessen, J., and Maskin, E. 2000. Sequential innovation, patents and imitation. Working Paper. Cambridge, MA: Department of Ecomics, MIT; Schwartz, M. A. 1978. The imitation and diffusion of industrial innovations. Ann Arbor: University of Michigan Press; Mansfield, Schwartz and Wagner, Imitation costs and patents: An empirical study: Levin et al., Survey research on R\&D appropriability and technological opportunity.

6. Hawley E. W. 1966. The New Deal and the Problem of Monopoly: A Study in Economic Ambivalence. Princeton: Princeton University Press.

7. Meyer J. W. 1981. Remarks at ASA Session on «The Present Crisis and the Decline in World Hegemony». Toronto, Canada.

8. Dr.YKK (Kam Keong Yew) Copycat Innovation: The Unbeatable Fast-track Route to Profitable Innovation, 2011 // www.mindbloom.net

9. http://www.innovationmanagement.se/imtool-articles/copycat-innovation-a-practical-route-to-profitable-innovation/
10. http://www.selfgrowth.com/articles/copycat-innovation-your-secret-weapon-to-trounce-your-competition

\section{References (transliteration):}

1. Bogdanov A.A. Tektologiya. Vseobshchaya organizatsionnaya nauka. M.: Finansy, 2003

2. Mishin S.A. Proektnyi biznes. Adaptirovannaya model' dlya Rossii . -M.:AST, 2006

3. P. Dzh. Dimadzhio, U. V. Pauell Novyi vzglyad na «zheleznuyu kletku»: institutsional'nyi izomorfizm i kollektivnaya ratsional'nost' $\mathrm{v}$ organizatsionnykh polya// Ekonomicheskaya sotsiologiya. T. 11. № 1. Yanvar' 2010

4. O. Shenkar Imitatory. Kak kompanii zaimstvuyut i pererabatyvayut chuzhie idei, M.: Al'pina Pablisherz, 2011

5. Bessen, J., and Maskin, E. 2000. Sequential innovation, patents and imitation. Working Paper. Cambridge, MA: Department of Ecomics, MIT; Schwartz, M. A. 1978. The imitation and diffusion of industrial innovations. Ann Arbor: University of Michigan Press; Mansfield, Schwartz and Wagner, Imitation costs and patents: An empirical study: Levin et al., Survey research on R\&D appropriability and technological opportunity.

6. Hawley E. W. 1966. The New Deal and the Problem of Monopoly: A Study in Economic Ambivalence. Princeton: Princeton University Press.

7. Meyer J. W. 1981. Remarks at ASA Session on «The Present Crisis and the Decline in World Hegemony». Toronto, Canada.

8. Dr.YKK (Kam Keong Yew) Copycat Innovation: The Unbeatable Fast-track Route to Profitable Innovation, $2011 / /$ www.mindbloom.net 